\title{
Raising the volume: Indigenous voices in news media and policy
}

\author{
Kerry McCallum, Lisa Waller and Michael Meadows
}

\section{Abstract}

This paper explores Indigenous contributions to shaping public and policy agendas through their use of the news media. It reports on research conducted for the Australian News Media and Indigenous Policymaking 1988-2008 project' that is investigating the relationships between the representation of Indigenous peoples in public media and the development of Indigenous affairs policies. Interviews with Indigenous policy advocates, journalists and public servants identified the strategies that have been used by individuals and Indigenous organisations to penetrate policy debates and influence public policy. The paper concludes that in the face of a neo-liberal policy agenda amplified through mainstream media, particular Indigenous voices have nevertheless had significant impacts, keeping alive debate about issues such as the importance of bilingual education programs and community involvement in the delivery of primary health care.

\section{Introduction}

The Australian News Media and Indigenous Policymaking 1988-2008 project is investigating the relationships between the representation of Indigenous peoples in public media and Indigenous affairs policies. Our research emphasises the discursive nature of policymaking, arguing that Indigenous policies have been developed in an increasingly media saturated environment. Despite, or perhaps because of, the news media's frequently negative framing of Indigenous affairs, and little apparent gain for politicians who promote Indigenous policy reform, fierce contests persist over solutions available to address the range of Indigenous 'problems'. Those tasked with developing policy such as public servants, and those with an interest in influencing policy outcomes such as Indigenous representatives and communities, play out their battles discursively by trying to influence the way news media frame policy stories (Schön and Rein, 1984: 4; Gamson and Modgliani, 1989; Bacchi, 2009; KochBaumgarten and Voltmer, 2010). Media and journalism studies have concluded that mainstream reporting contributes to narrowing, sensationalising, or shutting down public debate (Jakubowicz et al., 1994; Meadows and Ewart, 2001; McCallum, 2007; 2010; Waller 2010). While this can certainly be the case, we argue that Indigenous policy advocates have played an important but largely unrecognised role in keeping alive debate about issues such 
as the importance of bilingual education programs and community involvement in the delivery of primary health care. At the same time there has been limited research exploring the ways in which they might contribute to shaping public and policy agendas through their various uses of the news media.

Our research focuses on particular policy fields - Indigenous primary health care and bilingual education. The delivery of primary health care via community controlled Aboriginal Medical Services (AMS) has had a chequered policy history, since the release and adoption of the 1989 National Aboriginal Health Strategy that advocated a strongly self-determinist model of primary health care (Murray et al, 2003). Despite policies of mainstreaming during the 2000s that attacked their underlying principles, the AMS network of more than 140 services has survived to play an important role in the Federal Government's 'Closing the Gap' policy to improve the life expectancy of Indigenous Australians. Likewise, bilingual education policies in the Northern Territory have been the subject of controversial policy shifts since their inception in the 1970s. In 1998-99 the Northern Territory Government attempted to abolish the programs in remote Indigenous communities (Hoogenraad, 2001: 131), a move that was fiercely contested by Indigenous and education communities. Bilingual education programs survived until 2008, when the NT government effectively abolished them with the decision that the first four hours of teaching per day would be in English.

Understanding the discursive nature of policy requires an approach that identifies and theorises the contested sources of knowledge at play regarding Indigenous health and bilingual education policy debates. While the analysis of media and policy texts plays an important part in the Australian News Media and Indigenous Policymaking 1988-2008 project, this paper reports on the knowledge and media practices (Couldry 2004) of policy actors. Through the qualitative analysis of more than 50 interviews with journalists, Indigenous policy advocates and public sector workers we identify common and contested themes in their conversations about the practices involved in developing, influencing or reporting on Indigenous policy in the 20 years from 1988 to 2008. A range of mechanisms have enabled Indigenous people to penetrate public policy debates, define problems for policymaking and public discussion through the news media, and thereby exert particular forms of influence in the policy process. We are particularly interested in the intersection of 'Indigenous public spheres' and mainstream journalism, and the pressure that such relationships can exert on policymakers and policy outcomes at key policy moments. 


\section{News media and the policymaking process}

The effects of news media on public policy have long preoccupied media and communication scholars. Early British media studies (e.g. Cohen and Young 1973) provided a textual approach to identifying the primary role of the news media in defining policy problems. Political communication research has emphasised the effects of news media content on political cognition through studies of agenda-setting and framing, with an emphasis on political campaigns (McCombs 2004; Blumler and Gurevitch 1995; Bennett and Entman 2001; McNair 2007). Policy agenda-setting research examines the indirect influence of media on policy elites, for whom news media coverage is a public opinion indicator (Herbst, 1998; Bakir, 2006), but such research does not fully address the complexities of the news media's role in the policymaking process.

Davis' (2007) and Koch-Baumgarten \& Voltmer's (2010a) recent surveys of scholarship on the relationship between media and policy development processes call for a more nuanced examination of the news media's role in identifying policy problems, influencing policy solutions and disseminating policy outcomes. It is argued that the policymaking field has become increasingly 'mediatised' (Fairclough 1995) whereby 'media have 'colonised' the political process by imposing their operational logic on the institutional procedures of public policy' (Voltmer and Koch-Baumgarten, 2010: 4). Althiede and Snow (1979) coined the term 'media logic' to represent the way newsworkers' professional routines impact on policy processes and outcomes (see also Strömbäck and Dimitrova 2010; Couldry, 2003). Bacchi (2009) highlights the discursive activities of governments in actively producing and representing policy problems, and Ward (2007) and Davis (2007) document the growth of government communications and media management. Our project emphasises the discursive nature of Indigenous policymaking by examining both the mediated outputs of journalism and policy and the media practices of policy actors. The notion that Indigenous policy has largely been played out in the public sphere challenges and complicates traditional policy analyses that tend to see news as external to the policy process. However, it is useful for understanding 'intractable' policy disputes which are enduring and seldom resolved, such as Indigenous health and education. According to Schön and Rein (1984: 26), in intractable policy disputes, actors narrate firmly held but contested frames and agendas with the intention of influencing news media reporting and, ultimately, policy outcomes. We argue that news media provide an important platform for discursive battles over policy definitions and solutions (Gamson and Modgliani, 1989; Terkildsen et al., 1998). 


\section{Mainstream media representation and Indigenous public spheres}

News media representation is one important element of the discursive policymaking process. Media studies have concluded that news reporting overwhelmingly represents Indigenous Australians as a source of societal risk and problematic for the mainstream, and that Indigenous policy is generally only of interest when it meets a narrow range of news values, most importantly conflict and proximity to political elites (Jakubowicz et al., 1994; Mickler, 1998; Meadows, 2001; Meadows and Ewart, 2001; McCallum, 2007; 2010; 2011). Ultimately, journalism studies researchers have concluded that the reporting of Indigenous policies supports an agenda that promotes individual responsibility over a collective responsibility to ensure social justice, or a rights agenda that supports the selfdetermination of Indigenous peoples (Jakubowicz et al., 1994; Meadows, 2001). Cottle (2000: 9; see also Hartley \& McKee 2000) has argued that this research tradition, while important, has sometimes led to 'a fairly static and uniform picture of ideological or representational closure, and in the process tends to cover over the historical processes of change'.

In response to Cottle's call to look beyond racist journalism in mainstream public spheres as an explanation for the perpetuation of stereotypical reporting and poor policy outcomes, we have identified a body of research that examines the efficacy of marginalised groups in the public discussion of intractable policy disputes (Bakir 2006; Dreher 2010; Lester and Hutchins 2009). Marginalised groups including Indigenous Australians have limited access to the formal channels of influence in ministries and bureaucracies compared with established interest groups, for example, mining companies (Maddison, 2009). They therefore have little choice but to use the news media to convey their concerns to policymakers:

They depend on mass media to relay their demands; public pressure is their only source of power. So they enter into political alliances with the media to establish themselves in the political field and put their concerns on the political agenda (KochBaumgarten and Voltmer, 2010b: 224).

In her study of a public contest over framing an environmental risk, Bakir (2006) argued that environmental groups were able to compete with corporate interests to act as information 'sponsors', using media coverage and public opinion to pressure governments and influence policy outcomes (Gandy, 1982). Lester and Hutchins (2009) examined the 'tactical' media activities of environmental activists, while Dreher (2010) examined the way Muslim 
community media interventions enabled one marginalised community to respond to mainstream media representation.

A number of studies have examined the way Indigenous peoples develop their own public spheres and have actively promoted and responded to issue frames (Hartley \& McKee, 2000; Avieson \& Meadows, 2000; Hartley, 2003; Meadows, 2005; Tafler 2005). Working in Habermas's (1989) public sphere tradition, Hartley and McKee (2000) first coined the term 'indigenous public sphere'. They argue that indigenous people are not passive recipients of media representation. Rather, they produce their own media and actively use it for selfrepresentation and community-building. Hartley (2003: 46) argued for a rethinking of public spheres to 'one that emphasises the way communities can come together, define identities and 'represent' themselves in a virtual sense, in and through the media'. However, this early research is mainly concerned with how indigeneity is constructed within the wider public sphere. Further studies (Avieson and Meadows 2000, Meadows 2005; Tafler 2005) have explored how the communication and governance processes of traditional Indigenous public spheres inform and shape indigenous public sphere activity. In other words, they offer ways for understanding how Indigenous people 'make themselves' within their own public spheres and the implications that flow from this, including how these deliberations are then able to interact with the wider public sphere (Meadows 2005:38).

This paper argues that the intractability of Indigenous policy issues arises in part from the effectiveness of Indigenous peoples in maintaining and promoting their firmly held cultural and political perspectives on issues such as health and education in public and media discussion. Mickler (1998) argues that in spite of stereotypical mainstream media coverage, negative public opinion, and an unsupportive political environment, Indigenous peoples have become key media players. Policies of self-determination from the 1970s empowered Indigenous peoples to affect their own representation, through the funding of Indigenouscontrolled organisations and the emergence of Indigenous owned and operated media. Our interviews provide empirical evidence to show how Indigenous policy advocates use Indigenous public spheres and engage with mainstream media and culturally competent journalists to keep their policy agendas alive.

\section{Research approach}

The Australian News Media and Indigenous Policymaking 1988-2008 project has identified and analysed the contested sources of knowledge at play in the policymaking process, 
including news and policy texts. As Gamson (1992) reminds us, news analysis sheds only partial light on the processes at play in the production, public debate and dissemination of specific policies. We argue that the local understandings of journalists, policy advocates and policymakers are an important but understudied facet of the policymaking process. We draw on the scholarship of British media studies academic Nick Couldry who has proposed the study of 'media-related practices' as a useful theoretical framework for investigating precisely how the media shapes different areas of social life (Couldry, 2004). Couldry says the way to begin such a study is to find out what people say and what they do in relation to the media. This open approach is being used here for mapping the subtleties and complexities of the interactions among journalists and others in Indigenous policy networks and to theorise how media logics are naturalised and embodied by some policy actors.

Depth interviews with individuals and groups are one methodological approach used to access the professional and personal perspectives, viewpoints and knowledge of actors in a particular policy field (Gamson, 1992; Herbst, 1998; Davis, 2007; McCallum, 2010; Forde, et al., 2010). Our project built on established approaches to depth interviewing, to allow participants in the policymaking process to articulate their own perspectives and understandings about the relationships between media reporting and Indigenous policy. We conducted some 50 interviews with federal and state public servants, former ministerial advisers, communication specialists, community-based Indigenous organisations, Indigenous media workers, and current and former journalists reporting on Indigenous affairs.

Interview participants shared personal experiences of developing, promoting, influencing and reporting particular policies, expressed opinions about the role of media, and reflected on their own professional practices. We used inductive qualitative analysis to develop themes from the content of participants' dialogue in concert with relevant academic literature (cf Hartley and McKee's (2000) 'parliamentary' approach that documented without interpreting their participants' words). Through the talk of these policy actors, we identified the strategies used by Indigenous policy advocates - those outside of the formal policymaking process including Indigenous community members, non-government advocacy groups, and established Indigenous leaders - to influence the development of Indigenous policy through their engagement with the news media. Exemplar quotes are used to illustrate each theme, and only those who nominated not to remain anonymous are named in this article. 


\section{Indigenous policy advocates' media practices}

Indigenous public spheres

A number of study participants offered precise insights into how Indigenous public spheres function and provided evidence of the ways in which these processes impact on the mainstream public sphere. Participants emphasised the central role of Indigenous media outlets as forums for people to deliberate together and advance their own policy discourses. Former $A B C$ journalist and Indigenous media consultant Ursula Raymond was hired by Yolgnu in North-East Arnhem Land to assist in their campaign to retain bilingual education programs. She said:

... They're doing that stuff through their own local media networks, Indigenous radio, the national Indigenous radio service and their own Koori radio, radio Larrakia, CAAMA, those sorts of places.

News is constructed through co-operation between journalists and their sources who maintain close contact and shared values. Participants in our study described the relationship between Indigenous media organisations and their sources from the Aboriginal community in terms of confidence and familiarity. One said:

The people out there, they utilise Indigenous media a lot of the time off their own bat anyway. They knew them and they just worked them.

Communities and independent Indigenous organisations embody media logic by drawing on media expertise from within their own spheres to teach people to use digital technologies to create and operate their own media. As well as investing in the services of Indigenous media consultants to co-ordinate specific campaigns and strategies, large Indigenous organisations provide spokespeople with formal media training and operate in-house media services. Former Apunipinna Cape York Health Council executive director Kerry Arabena discussed the importance and value of media expertise within her organisation and for its stakeholders:

... up in Cape York I invested in my own communications unit. So we actually had through the Cape York Health Council, our own communications unit, including digital media, print media. We made a lot of media statements. We went out to communities to help them generate media about their own successes. 


\section{Engaging mainstream media}

Engaging with the mainstream media is a key strategy for penetrating public policy debates. Participants identified a range of mechanisms for engagement from sophisticated 'media machines' within Indigenous organisations to people on the ground using media logic to promote their messages. Raymond attributed the effectiveness of the bilingual education campaign in 1998-9 to her Yolgnu clients being 'media savvy':

They understood the media, they understood the messages that they wanted to get out so they knew how to work that ... They were very open to talking to the media. They had their key spokespeople identified and prepped and ready to go and they were unified on the issue and very clear.

She reflects the earlier comments of the Koori Mail's Todd Condie when he said:

Increasingly, Indigenous people are becoming 'media savvy', which means mainstream media will always be looked at to further a particular message or viewpoint...To be fully effective, media-savvy Aborgines know to use both the mainstream and Indigenous networks to state their case' (quoted in Hartley, 2003:53).

Trying to ensure their perspectives are heard loud and clear in the mainstream media is crucial for Indigenous people who want to counter their political opponents. One participant expressed the importance of using the same media tactics as other policy actors. She said her organisation always aimed to advance its policy positions:

... in the same kinds of formats and in the same kind of arenas where they chose to take us on.

Arabena said:

I think what they expected was that we wouldn't have a voice to give back, but in fact a lot of us were influential in The Age, in The Weekend Australian and in our own media, and I think, we were very successful.

However, participants were not universally positive about their chances of being listened to by mainstream media. Some commented that in certain climates it was more disposed to 
picking up Indigenous perspectives or responding than at other times. For instance, during the Howard years when there was a push to mainstream Indigenous health services the community-controlled sector found it very difficult to gain a voice. Former CEO of the National Aboriginal Community Controlled Health Organisation (NACCHO), Steve Larkin, said:

I came to understand how fickle the media could be...I found there wasn't much interest....in any sort of positive stories, and I know I'm not the first person to say that.

The pivotal place of Indigenous spokespeople

Established Indigenous leaders can wield considerable influence in public and policy discussions through their use of the mainstream news media as a platform to advance their agendas and take on their opponents. Participants identified effective leaders as those with well-developed media skills. Raymond said:

There are some like Galarrwuy Yunipingu who's incredibly sharp and knows how to work the media.

These leaders have two roles in the mainstream media. They are busy actors on the political stage and therefore often-quoted news sources and providers of 'news subsidies' (Gandy 1989; Bakir 2006). Some have also developed strong profiles and influential voices through the opinion pages of the national Press. Some are regular contributors, such as Noel Pearson, who writes for The Australian, while others such as Marcia Langton, Warren Mundine and Galarrwuy Yunipungu appear as guest columnists and opinion writers.

Arabena observed that:

Noel [Pearson] used media with a stunning success and really did engage the eye of mainstream Australia, really. He was able to communicate very effectively through media networks that we had within all of the Cape York institutions.

However, many participants were critical of the lack of diversity of Indigenous leaders' voices heard in the mainstream media and said some conservative leaders' views had become too dominant in both public and policy discussions. A lack of strong Indigenous 
leadership can make it difficult to attract media attention. Former Yirrkala principal Leon White said in 1998 Yolgnu had leaders with national media profiles, including Yothu Yindi lead singer Mandawuy Yunipingu. In 2008, when Yolgnu experienced difficulty attracting media attention for their campaign to save bilingual education, these leaders were no longer in the community due to death or ill-health. Reflecting on the success of the 1998 campaign, White lamented that:

We also had people like [internationally renowned Yolgnu educator] $\mathrm{Dr}$ Marika who's now passed away and Mandawuy's wife and others who took leadership of this. They're no longer with us.

\section{Journalists' competence and orientations}

Journalists play a crucial role in mediating Indigenous voices in the mainstream public sphere. They can amplify Indigenous policy perspectives, or downplay them. Different journalism practices and journalists' personal orientations produce different levels of engagement, which results in an uneven landscape in the reporting of Indigenous issues. Most participants commented that lack of empathy for Indigenous issues and people contributed to poor journalism practice and negative portrayals.

Participants identified particular journalists who have the cultural competence to negotiate Indigenous public spheres. These are the reporters who are most likely to actively seek out and represent Indigenous policy agendas and perspectives, forming valuable intersections between the Indigenous public sphere and the mainstream. Journalists' personal histories and experiences influence their approaches. A number declared they were committed to presenting positive accounts about Indigenous people and highlighting injustice. Some described themselves as having a social justice orientation, while others said early reporting experiences had shaped their attitudes. Veteran Press Gallery journalist Peter Reese recalled his earliest experiences in the 1970s:

So to ... have these events unfolding before my eyes and ... witness police brutality - dragging people like Bobby Sykes ... off on their backs along the ground and throwing them in the paddy wagon - it really opened my eyes and made me very aware of the disparity in society that Aboriginals have. 
Former National Indigenous Times writer Graham Ring said the social justice orientation in his journalism came from his Catholic school education and studying politics at university:

I was always pondering how ... you give people a feeling for the kind of discrimination, mistreatment, dispossession all that kind of stuff, it clearly wasn't cutting through the [journalism] that was around.

Murray McLaughlin of the $A B C$ said some may criticise him for ignoring the hard and more negative stuff':

... but it's been my preference to look for stories and actively pursue stories that have positive contexts ... It's not all ... doom and gloom ... I don't know how that developed, but it's just the way it's worked out.

Participants identified cultural competence as the key attribute of accomplished Indigenous affairs reporters. They said it enabled them to find their own stories, cultivate and maintain strong contacts in the Indigenous public sphere and negotiate the obstacles in the field to get the story. $A B C$ reporter Katrina Bolton said:

If you don't know how to be culturally aware with traditional people especially, then it doesn't matter how much you try to make eye contact you're not going any further.

A number of journalists said they gained their cultural competence while working in different roles for Indigenous bodies. Others learned in the field from other professionals with deep experience living and working with Indigenous peoples. Chips Macinolty worked with Indigenous organisations for many years before writing for mainstream publications. He said he did not find it difficult to find agenda-setting issues:

I remember when I was working for the [Sydney Morning] Herald I was getting pages 1,3 and 5 really regularly because the stories I was getting were really fantastic.

Senior writer with The Australian, Tony Koch, has developed a strategy for enabling Indigenous people from remote communities to gain access to him and generate news stories: 
What I do in Queensland, and it's a bit of a sneaky one, but it works. With News Ltd, we've got a 1300 number so you can ring free from any phone anywhere in Australia. And I just put that number all around, all the communities, anywhere, on cards, anyone that wants to talk to me can just pick up the yellow phone.

\section{Policymakers' media practices}

National Indigenous Times' Chris Graham explained that in order influence policy, Indigenous organisations ultimately needed to engage with mainstream media, and Indigenous publications were an important connection between the two:

One of the things we did well and the reason we survived and thrived is, we would use the media to break a story, knowing full well if we broke a great story it would make a heap of difference. Because if the mainstream media didn't pick it up, the government wouldn't ... because politicians are so easily influenced by what the media say.

Participants made direct links between effective media strategies and success in influencing the policy process. Arabena said that through the work of the Cape York Health Council's communications unit:

We were able to influence policymakers, community leaders. We were able to send out newsletters that had the eye of the ministers and as a result of our media campaigns we were able to change policy.

Interviews conducted with federal and state public servants and former ministerial advisers provide evidence of how news media coverage and debate influences their policy practices (McCallum, unpublished). These participants are reflexive about their role in a media saturated policy environment. They acknowledge they use the media strategically to promote their policies to the public, that their practices feed the journalists' routines and react to minister's political agendas. The political sensitivity of Indigenous health policy means that any sharp focus by news outlets, particularly The Australian and talkback radio, is likely to have some policy impact. One senior health bureaucrat said:

You have to be aware of the political implications of what's going to happen if something you do goes public. Is it a good news story or a bad...if it's not saleable to 
the general public...then if you've got a strong enough case they'll do it covertly...or it won't happen, or it will be defused rather than put in place something that...the talkbacks or the tabloids might get a hold of...'

Participant Tess Lea was one of the authors of Learning Lessons (Collins, 1999), the report of the Collins review of indigenous education in 1999 that led to the Northern Territory's bilingual education policy being reinstated as 'two way learning'. She offers precise insights into how Indigenous public sphere activity defused the government's policy resolve. She said the Northern Territory Government's terms of reference for the inquiry did not include bilingual education. However, the 'Don't cut off our tongues' campaign was so successful in focusing public and news media attention that 'no one wanted to talk about anything else':

... So we took that on as it was a responsibility to try to find some kind of middle path ... so we came up with ... two-way stuff ...it was really just trying to navigate through government's ordained decision and what was clearly needed on the ground ... So that's what happened, it [the inquiry] was gazumped, the issue gazumped us.

\section{Conclusions}

This paper has identified some of the mechanisms that enable Indigenous people and communities to make incursions into public policy debates and ultimately affect policy outcomes. This story is told through the words of those who have fought on behalf of particular policy outcomes in Indigenous health and education, those involved in reporting on Indigenous policy in Australia, and those who develop and implement that policy. Indigenous community activists take a strong position in policy debates that affect them, based in their culture and their land. We have argued that in a mediatised policymaking environment, these communities have effectively used Indigenous public spheres to engage with mainstream media to keep their policy agendas alive.

Yolgnu people's campaign to retain bilingual education culminated in the biggest ever petition to the NT parliament, and resulted in the retention of these programs for another decade. We argue that if Yolgnu had not employed news media strategies and tactics to engage with the policy debate, bilingual education in the Northern Territory would have been scrapped a decade earlier. Similarly, we have demonstrated that despite marginalisation over many years in national health policy debates, the media activities and commitment of policy advocates to the self-determinist principles of Aboriginal community 
controlled health contributed to the survival of the AMS network in the delivery of primary health care to Indigenous Australians.

Media savvy Indigenous leaders understand journalism's role in defining policy problems and providing a platform for a range of voices to be heard in policy debates (Mickler, 1988). Advocates interviewed for this study believe the media plays an important role in policymaking, and have employed a range of mechanisms to engage with and influence national policy debates. This finding supports Koch-Baumgarten and Voltmer's (2010) argument that marginalised groups rely on mass media to amplify their demands in public discussion. They understand the importance of engaging empathetic journalists in the mainstream media, in order to get their policy positions heard. Whether it is through communications units developed in Indigenous-controlled health organisations, or the promotion of news stories broken in Indigenous media, there is an acceptance that Indigenous public spheres must engage with mainstream public spheres in order to influence government policy. In this way, Indigenous organisations employ media logic in their campaigns to affect policy change.

While our paper recognises the marginalisation of Indigenous viewpoints in mainstream media reporting, we have identified a small group of journalists who have the skills and commitment to amplify Indigenous perspectives in public discussion. There are journalists who have the cultural competence and professional practices to negotiate Indigenous public spheres effectively, enabling them to broaden public and policy debates. They typically have a social justice orientation and a genuine desire to engage with Indigenous public spheres. They do not, however, see themselves as mouthpieces for Indigenous causes or their role as influencing policy, but they do articulate a desire to make a difference to the lived experience of Indigenous people. These agenda-setting journalists often break the big stories that initiate major policy change. Their reporting does not always promote 'good' policy as the Indigenous advocates we have interviewed would understand it, but they maintain a commitment reporting Indigenous perspectives.

In a mediatised policymaking environment it is imperative that Indigenous voices are heard (Dreher 2010). There is a diversity of peoples and opinions in Indigenous Australia, however, not all voices are heard at the same volume. Some are diminished in the cacophony of crisis and sensation generated on the floors of parliaments and newsrooms. But there is a determination to convey Indigenous agendas to those in power and engage in the 
policymaking process. As Maddison (2009: xxvi) says, Aboriginal people are tasked with negotiating a complex political culture that is poorly understood by non-Aboriginal people, but in doing so, they are 'resourceful, creative and persistent'.

\section{References}

Althiede, David and Robert P. Snow, 1979, Media logic, Beverly Hills, Sage.

Altman, Jon \& Melinda Hinkson (eds), 2010, Coercive reconciliation: stabilize, normalize, exit Aboriginal Australia, Carlton, Arena.

Avison, S., \& Meadows, M., 2000. Speaking and hearing: Aboriginal newspapers and the public sphere in Canada and Australia. Canadian Journal of Communication, 25, pp.347-366.

Bacchi, Carol, 2009, Analysing policy: what's the problem represented to be?, Frenchs Forest, Pearson.

Bakir, Vian. 2006, 'Policy agenda setting and risk communication', Press/Politics 11(3), pp. 67-88.

Bennett, W. Lance and Entman, Robert, 2001, Mediated politics: communication in the future of democracy, Cambridge, Cambridge University Press.

Blumler, Jay G. and Gurevitch, Michael, 1995, The crisis of public communication, Routledge, New York.

Cohen, Stanley and Young, Jock, 1973, The manufacture of news: a reader, Beverly Hills, Sage.

Collins, B., 1999. Learning lessons: An independent review of Indigenous education in the Northern Territory. Darwin: Northern Territory Department of Education.

Cottle, Simon, 2000 'Media Research And Ethnic Minorities: Mapping The Field' in Ethnic minorities and the media: changing cultural boundaries, Buckingham, Open University Press, pp. 1-31.

Couldry, Nick, 2003, 'Media meta-capital: Extending Bourdieu's field theory', Theory and Society 32(5/6), pp. 653-677. 
Couldry, Nick, 2004, 'Theorising media as practice', Social Semiotics 14(2), pp. 115-132.

Davis, Aeron, 2007, Investigating journalist influences on political issue agendas at Westminster, Political Communication, 24(2), p. 181-199.

Dreher, Tanja, 2010, 'Speaking up or being heard? Community media interventions and the politics of listening', Media Culture and Society 32(1), pp. 85-103.

Fairclough, Norman, 1995, Media discourse, London \& New York, Arnold.

Forde, Susan, Foxwell, Kerry, \& Meadows, Michael, (2010). Developing dialogues, Indigenous \& ethnic community broadcasting in Australia, Chicago, University of Chicago Press.

Gamson, William A, 1992, Talking politics, Cambridge, Cambridge University Press.

Gamson, William A. and Modigliani, Andre, 1989, 'Media Discourse and Public Opinion on Nuclear Power: A Constructionist Approach', The American Journal of Sociology 95(1), pp. 137.

Gandy, Oscar H., 1982, Beyond agenda setting: information subsidies and public policy, Norwood, NJ, Ablex.

Habermas, Jurgen, 1989, The structural transformation of the public sphere, Cambridge, MIT Press.

Hartley, John, 2003, 'Their own media in their own language', in C. Lumby and E. Probyn (eds), Remote control: new media, new ethics, Cambridge, Cambridge University Press.

Hartley, John and McKee, Alan, 2000, The Indigenous public sphere, Oxford, Oxford University Press.

Herbst, Susan, 1998, Reading public opinion: How political actors view the democratic process, Boulder, CO, Westview Press.

Hoogenraad, Robert, 2001, 'Critical reflections on the history of bilingual education in Central Australia,' in J. Simpson, D. Nash, M. Laughren, P. Austin and B. Alpher, (eds.) Forty Years On, Canberra, Pacific Linguistics. 
Jakubowicz, Andrew, Jeannie Martin, Tony Mitchell, Lois Randall, Heather Goodall and Kalinga Seneviratne, 1994, Racism, Ethnicity and the Media, St Leonards NSW, Allen \& Unwin.

Koch-Baumgarten, Sigrid and Katrin Voltmer (eds.), 2010a, Public policy and mass media, London, Routledge.

Koch-Baumgarten, Sigrid and Katrin Voltmer, 2010b 'Conclusion', in (eds.), 2010, Public policy and mass media, London, Routledge, 215-225.

Lester, Libby and Hutchins, Brett, 2009, 'Power games: environmental protest, news media and the internet', Media, Culture and Society 31(4), pp. 579-595.

Maddison, Sarah, 2009, Black politics: Inside the complexity of Aboriginal political culture, Sydney, Allen \& Unwin.

McCallum, Kerry, 2007, Public opinion about Indigenous issues in Australia: Local talk and journalistic practice, Gold Coast, Griffith University Press.

McCallum, Kerry, 2010, 'News and local talk: Conversations about the crisis of 'Indigenous Violence' in Australia,' in The anthropology of news and journalism: Global perspectives, S. Elizabeth Bird (ed), Bloomington, IN, Indiana University Press.

McCallum, Kerry, (unpublished), 'Managing the optics: Media representation and Indigenous policymaking', paper delivered to the Australian Political Science Association annual conference, 26-28 September 2011, Canberra.

McCallum, Kerry, 2011, 'Journalism and Indigenous health policy', Australian Aboriginal Studies 2011/2, pp. 21-31.

McCombs, Maxwell, 2004, Setting the Agenda: The Mass Media and Public Opinion, Cambridge, UK, Polity Press. 2004

McNair, Brian, 2007, An Introduction to political communication (4 ${ }^{\text {th }}$ ed.) London, Routledge. Meadows, Michael, 2005, 'Journalism and indigenous public spheres' Pacific Journalism Review 11(1), p. 36-41.

Meadows, Michael, 2001, Voices in the Wilderness: Images of Aboriginal people in the Australian media, Westport, Greenwood Press. 
Meadows, Michael and Ewart, Jacqui, 2001, 'Journalism practices and Indigenous affairs', in S. Tapsell and C. Varley (eds) Journalism Theory in Practice, Melbourne, Oxford University Press, pp. 87-102.

Mickler, Steve, 1998, The myth of privilege: Aboriginal status, media visions, public ideas, Fremantle, Fremantle Arts Centre Press.

Murray, Richard, Bell, Kathy, Couzos, Sophia, Grant, Maggie \& Wronski, lan, 2003, 'Aboriginal health and the policy process', in S. Couzos \& R. Murray (Eds), Aboriginal primary health care: an evidence-based approach, Melbourne, Oxford, pp. 1-37.

Schön, Donald and Rein, Martin, 1994, Frame reflection: toward the resolution of intractable policy controversies, New York, Basic Books.

Spitzer, Robert, 1993, Media and public policy, Wesport, Praeger.

Strömbäck, Jesper and Dimitrova, Daniela V., 2010, 'Mediatization and Media Interventionism: A Comparative Analysis of Sweden and the United States', The International Journal of Press/Politics 16(1), pp. 30-49.

Tafler, David. I., 2005, 'Rolling thunder: Changing communication and the Pitjantjatjara Yankunytjatara public sphere' Pacific Journalism Review, 11(1), pp. 155-173.

Terkildsen, Nayda, Schnell, Frauke I. and Ling, Cristina, 1998, 'Interest groups, the media, and policy debate formation: An analysis of message structure,' Political Communication 15(1), pp. 45-61.

Voltmer, Katrin and Koch-Baumgarten, Sigrid, 2010, 'Introduction: Mass media and public policy - is there a link?' in S. Koch-Baumgarten and K. Voltmer, 2010, Public policy and mass media, London, Routledge, pp. 1-13.

Ward, Ian, 2007, 'Mapping the Australian PR state', in S. Young, Government communication in Australia, pp. 3-18.

Waller, Lisa, 2010, 'Singular influence: mapping the ascent of Daisy M. Bates in popular understanding and Indigenous policy', Australian Journal of Communication, 37(2), pp. 1-14. 
${ }^{i}$ Research for this paper was conducted as part of the Australian Research Council Discovery Project Australian News Media and Indigenous Policymaking 1988-2008 (DP 0987457) 